Article

\title{
Can MERRA-2 Reanalysis Data Reproduce the Three-Dimensional Evolution Characteristics of a Typical Dust Process in East Asia? A Case Study of the Dust Event in May 2017
}

\author{
Wenrui Yao ${ }^{1,2}$, Huizheng Che ${ }^{1, *} \mathbb{C}$, Ke Gui ${ }^{1,2}{ }^{\mathbb{D}}$, Yaqiang Wang ${ }^{1}$ and Xiaoye Zhang ${ }^{1}$ \\ 1 State Key Laboratory of Severe Weather (LASW) and Laboratory of Atmospheric Chemistry of CMA, \\ Chinese Academy of Meteorological Science, Beijing 10081, China; yaowenrui18@mails.ucas.edu.cn (W.Y.); \\ guik_ucas@163.com (K.G.); yqwang@cma.gov.cn (Y.W.); xiaoye@cma.gov.cn (X.Z.) \\ 2 College of Earth and Planetary Sciences, University of Chinese Academy of Sciences, Beijing 100049, China \\ * Correspondence: chehz@cma.gov.cn
}

Received: 23 January 2020; Accepted: 6 March 2020; Published: 11 March 2020

\begin{abstract}
This study used the MERRA-2 reanalysis dataset and ground-based and satellite observational data to comprehensively analyze a typical dust storm event in east Asia on 2-7 May 2017 which engulfed most of China as well as ocean and Japan, and explore the accuracy and comprehensiveness of the MERRA-2 dataset in the analysis of dust processes. The results of comparison show that the description of the spatiotemporal distribution and evolution of the dust aerosols in the dust event using the MERRA-2 data is consistent with the data of AERONET, National Urban Air Quality Real-time Publishing Platform and Hamawari-8. Gobi Deserts was the most influential source area of this dust event with the highest emissions reaching $1.9 \times 10^{6} \mathrm{\mu g} / \mathrm{m}^{3}$. The vertical motion of the atmosphere can lift dust from the source area above $500 \mathrm{hPa}$. There were low-pressure troughs at 500 and $850 \mathrm{hPa}$ and the winds behind and in front of the trough led to the high-altitude, long-distance transport of dust. Dust gradually affected the northwest China, north China, northeast China, and even the ocean and Japan on 2-7 May. This study demonstrates that although there is some uncertainty about the source of dust emission in the MERRA-2 model, the data accurately simulated the evolution of the dust event and analyze it comprehensively, while the accuracy of simulating the long-term evolution of dust requires further evaluation.
\end{abstract}

Keywords: MERRA-2 reanalysis dataset; dust; East Asia; high-altitude and long-distance transport; dust budgets

\section{Introduction}

The source, composition, and content of atmospheric aerosols have important effects on the atmospheric environment, human health, the social economy, ecology, and climate change. As an important component of tropospheric aerosols, approximately $(1-3) \times 10^{9} \mathrm{t}$ dust aerosol enter the atmosphere every year, accounting for about half of the total tropospheric aerosols. [1]. Dust can heat the atmosphere by absorbing solar shortwave and longwave radiation from the ground surface and clouds, and cool the atmosphere by scattering longwave and shortwave radiation and therefore influences the earth's radiation balance, which can affect the climate [2-4]. Dust can also indirectly change the microphysical properties of clouds by affecting the cloud condensation nuclei and ice cores, thereby affecting the efficiency of precipitation $[5,6]$. It can also change the albedo of snow and ice surfaces, exerting an indirect influence on the energy budget of the earth $[7,8]$. 
The dust in east Asia is sourced from China and surrounding areas and the annual emission of dust from this region accounts for about $25 \%$ of the global total, making it the second largest source of dust aerosols in the world [6,9].The Gobi Desert, the Taklimakan Desert, and the Loess Plateau are the main sources of dust in Asia [10-12]. However, the role of dust from the Gobi Desert in the earth's atmospheric system has been less well studied. Some studies have used the Cloud-Aerosol Lidar and Infrared Pathfinder Satellite Observation (CALIPSO) inversion and ground measurements to show that dust storms are more frequent over the Taklimakan Desert and that suspended dust is retained in the local area, whereas the dust storms in the Gobi Desert are less frequent, but more intense [11]. The time series of Multi-angle Imaging SpectroRadiometer (MISR) images shows that the Gobi Desert accounts for $>75 \%$ of the dust emission events in east Asia [13]. As a result of the long-distance transport of dust particles in the upper atmosphere, dust particles can change the atmospheric conditions at a regional or even global scale [14-16]. Dust aerosols from the Taklimakan and Gobi deserts can travel thousands of miles, affecting large areas of China [9,17-19], Korea and Japan [20], and even the north Pacific and North America [21,22].

In terms of the selection of data to analyze dust processes, satellite data are usually observed once a day, which is insufficient to describe the dust transport process and changes in detail. Models provide hourly simulation data, but contain high levels of uncertainty. Reanalysis data, which are available once every one hour or every three hours, can better depict the processes and evolution of dust events and analyze the mechanism of the event more comprehensively.

To explore the accuracy and comprehensiveness of the MERRA-2 dataset in the analysis of dust processes, MERRA-2 reanalysis data were selected to analyze a typical dust event that occurred in east Asia on 2-7 May 2017. The dust process influenced eastern, central, southern, and southeastern China, the east coast of China, including the Shandong peninsula and the Yangtze river delta, and reached Korea and Japan. The southward transport of dust caused high-altitude dust storms and southeastern Russia and the Sea of Okhotsk were affected by the long-distance transport of dust. The dust was sourced from the Taklimakan and Gobi deserts. The Gobi Desert was the main source area of the dust event; a temperate low-pressure system continuously passed through arid and semi-arid areas, intermittently causing dust emission in multiple source areas. The frequency of dust storms in the Gobi Desert was high before 2006, but decreased after 2008 [23]. Compared with the years before 2010, the number of days on which dust events were detected in Japan also decreased significantly after 2011 and this event was the largest dust storm event in Japan since 21 May 2010 [24].

We used MERRA-2 reanalysis data to conduct a comprehensive and multi-angle analysis of the dust event: (1) To compare the MERRA-2 reanalysis dataset with satellite remote sensing data, lidar data, and ground-based observational data to verify the accuracy of the MERRA-2 dataset in describing dust processes and the meteorological conditions; (2) to use the MERRA-2 dataset to analyze dust processes accurately and in detail, to study the evolution of the dust event and to test the ability of the MERRA-2 model to characterize the dust process; (3) to use the MERRA-2 reanalysis dataset and data from other sources to analyze the characteristics and causes of spatial and temporal distribution change of dust and the influence of the Gobi Desert on the transport process, the influencing factors and the dust budget in east Asia in this dust event.

\section{Data}

\subsection{MERRA-2 Reanalysis Dataset}

MERRA-2 is the latest atmospheric reanalysis dataset provided by NASA's global simulation and assimilation office [25]. Using the Goddard Earth Observing System Version 5 (GEOS-5), the Earth system model includes the circulation and composition of the atmosphere, the ocean circulation and land surface processes, and biogeochemistry [26,27]. The MERRA-2 dataset contains a large number of data, including the aerosol optical depth (AOD), surface forcing, the aerosol mixing ratio, the carbon monoxide and ozone mixing ratio, and radiation diagnosis. 
In addition to assimilating conventional observational meteorological data, MERRA-2 also provides a series of AOD datasets, including the offset-corrected AOD retrieved by the Advanced Very High Resolution Radiometer (AVHRR) and the Moderate Resolution Imaging Spectroradiometer (MODIS) onboard both the Terra and Aqua satellites [28,29] and the unbiased corrected AOD obtained from the MISR [30] on bright surfaces. Ground-based Aerosol Robotic Network (AERONET) observations [31] were also assimilated by the GEOS-5 Earth system model. Gelaro et al. (2017) provided an overview of the MERRA-2 modeling system and Buchard et al. (2017) gave a more detailed description of the aerosols in the MERRA-2 system [25,32].

Compared with the MERRA dataset, the aerosol data in MERRA-2 reduce false trends and the jumps associated with changes in the meteorological observation system. The data in MERRA-2 are rich, easy to obtain, with a long time series, global coverage, and an even distribution. We used the meteorological fields (vertical wind field, 500 and $850 \mathrm{hPa}$ wind fields, potential height, and temperature), aerosol concentrations (AOD550 $\mathrm{nm}$ and the dust aerosol mass concentration), and the dust aerosol mixing ratio in six different effective radius datasets (bin-001, 0-0.73 $\mu$ m; bin-002,

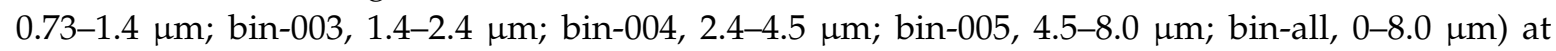
a resolution of $0.625^{\circ} \times 0.5^{\circ}$.

\subsection{Satellite Observations}

\subsubsection{Himawari-8}

Himawari-8/9 (https://www.eorc.jaxa.jp/ptree/index.html) is a new generation of geostationary meteorological satellite in Japan, it carries the most advanced optical sensor, the radiometric, spectral, and spatial resolution is significantly higher than sensors in the geostationary orbit before [33]. High resolution combined with shorter review times, provide new levels of capacity for the derivation of quantitative products and for the identification and tracking of rapidly changing weather phenomena [33]. The Advanced Himawari Imager on the Himawari-8 and 9 satellites can provide sub-daily observations of aerosol [33]. We used daily AOT data of Himawari-8 with spatial resolution of $0.5 \mathrm{~km}$ on 2-7 May 2017 to compare with MERRA-2 data.

\subsubsection{CALIPSO}

CALIPSO (https://www-calipso.larc.nasa.gov/), developed jointly by the United States and France, was successfully launched on 28 April 2006 to fill in the gaps in observations of aerosol and cloud properties and their global distribution. The main instrument carried on the satellite is the cloud aerosol Lidar CALIOP with cross-polarization, which is the lowest dual-wavelength (532 and $1064 \mathrm{~nm}$ ) polarization Lidar [34]. We used the CALIPSO aerosol products (cal_lid_12_05kmapro-standard-v4-10 and cal_lid_12_vfm-standard-v4-10) to analyze the transport distance and the range of influence of the dust in the 2017 dust events.

\subsection{Ground-Based Observations}

Figure $1 \mathrm{~b}$ shows the true color cloud image of the MODIS-TERRA satellite on 4 May 2017. The cloud image shows that the dust was transported to northern and northeastern China on 4 May 2017 and the areas affected by dust extended from northwestern to northeastern China, covering most of northern China. Based on the transport path of the dust, representative ground observation stations were selected to analyze the transport process and to verify the MERRA-2 data. 

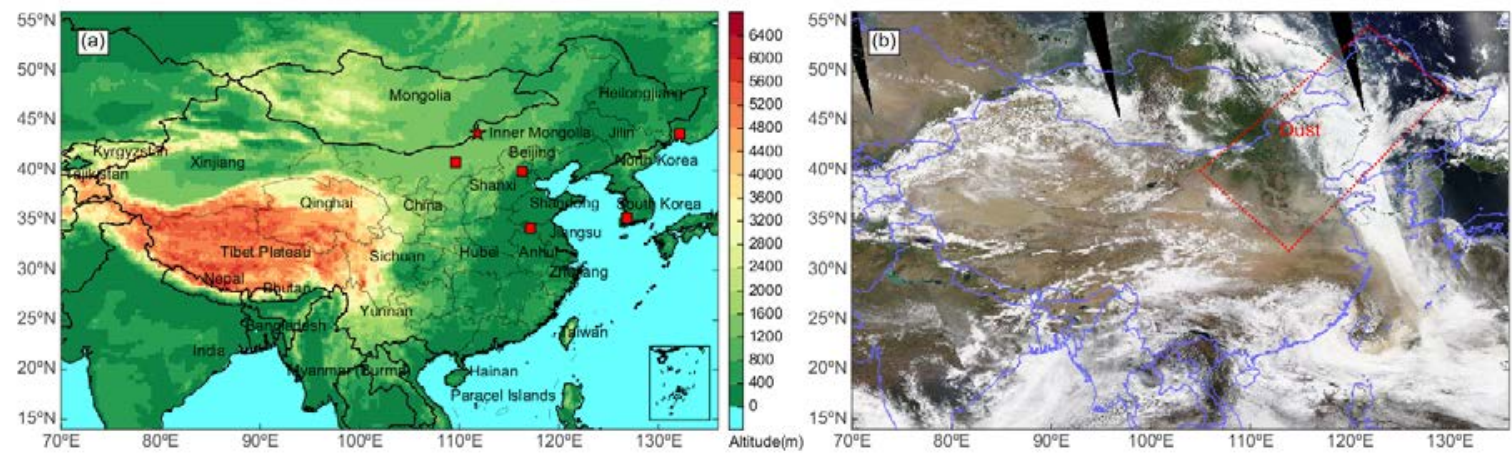

Figure 1. (a) Distribution of AERONET (red squares) and Lidar (red stars) stations. (b) MODIS-TERRA true color satellite cloud images on 4 May 2017.

\subsubsection{AERONET AOD Data}

The AERONET (https://aeronet.gsfc.nasa.gov/) program is an alliance of ground-based remote sensing aerosol networks jointly established by NASA and LOA-PHOTONS (CNRS). The AERONET collaboration provides globally distributed observations of the spectral AOD, inversion products, and precipitable water in diverse aerosol regimes. The network now covers all the major regions of the world and uses the CIMEL Electronique CE318 multiband sun photometer to measure the spectral irradiance of the Sun and the sky radiance [35]. The AERONET AOD data have a high accuracy and the uncertainty is about 0.01-0.02 [35]. These data play an important part in studies of global aerosol transport, aerosol radiation effects, and in verifying the radiation transmission mode and aerosol results from satellite remote sensing observations. Based on the direction of dust transport, we selected the hourly average AOD from five observation stations (Baotou, Beijing, Xuzhou, Ussuriysk, and Gwangju_GIST) to analyze the processes in this dust event and to verify the MERRA-2 reanalysis data.

\subsubsection{Lidar}

We selected the observation data from the lidar station in Inner Mongolia (Figure 1a) to analyze the transport and range of influence of the dust event. The Inner Mongolia Lidar data were obtained from the Asian Dust and Aerosol Lidar Observation Network (AD-Net). AD-Net is a Lidar network for the continuous observation of the vertical distribution of dust and other aerosols in east Asia [36]. AD-Net contributes to the WMO GAW Program and is the east Asian component of the GAW Aerosol Lidar Observation Network (GALION) [36].

\subsubsection{National Urban Air Quality Real-time Publishing Platform}

The National Urban Air Quality Real-time Publishing Platform (http://106.37.208.233:20035) is a platform for environmental monitoring stations in China to release the national air quality status according to the relevant provisions of the ambient air quality standards and the technical rules of the environmental air quality index (trial). The data are sourced from automatic national air quality monitoring stations (excluding local air quality monitoring stations). The platform is a real-time publishing platform and publishes both hourly and daily data as the reference value for each day. We selected the $\mathrm{PM}_{10}$ and $\mathrm{PM}_{2.5}$ data to analyze the dust process and verify the accuracy of the MERRA-2 data.

\section{Results and Discussion}

\subsection{Spatiotemporal Distribution of Dust}

We selected satellite and ground-based observational data and compared these with the MERRA-2 dataset to verify the accuracy of the MERRA-2 data in simulating the spatiotemporal distribution of dust. The comparison of Figure $2 \mathrm{a}, \mathrm{b}$ shows that the change in the spatiotemporal distribution 
described by the MERRA-2 reanalysis dataset is consistent with the change trend of the AOT of Himawari-8 during the dust event. The high values of the two data were different on 7 May, so we compared these data with the ground-based data in the following. The surface mass concentration is smaller than the column mass concentration, indicating that a large amount of dust was lifted high into the atmosphere during the dust event and traveled over long distances (Figure S1).
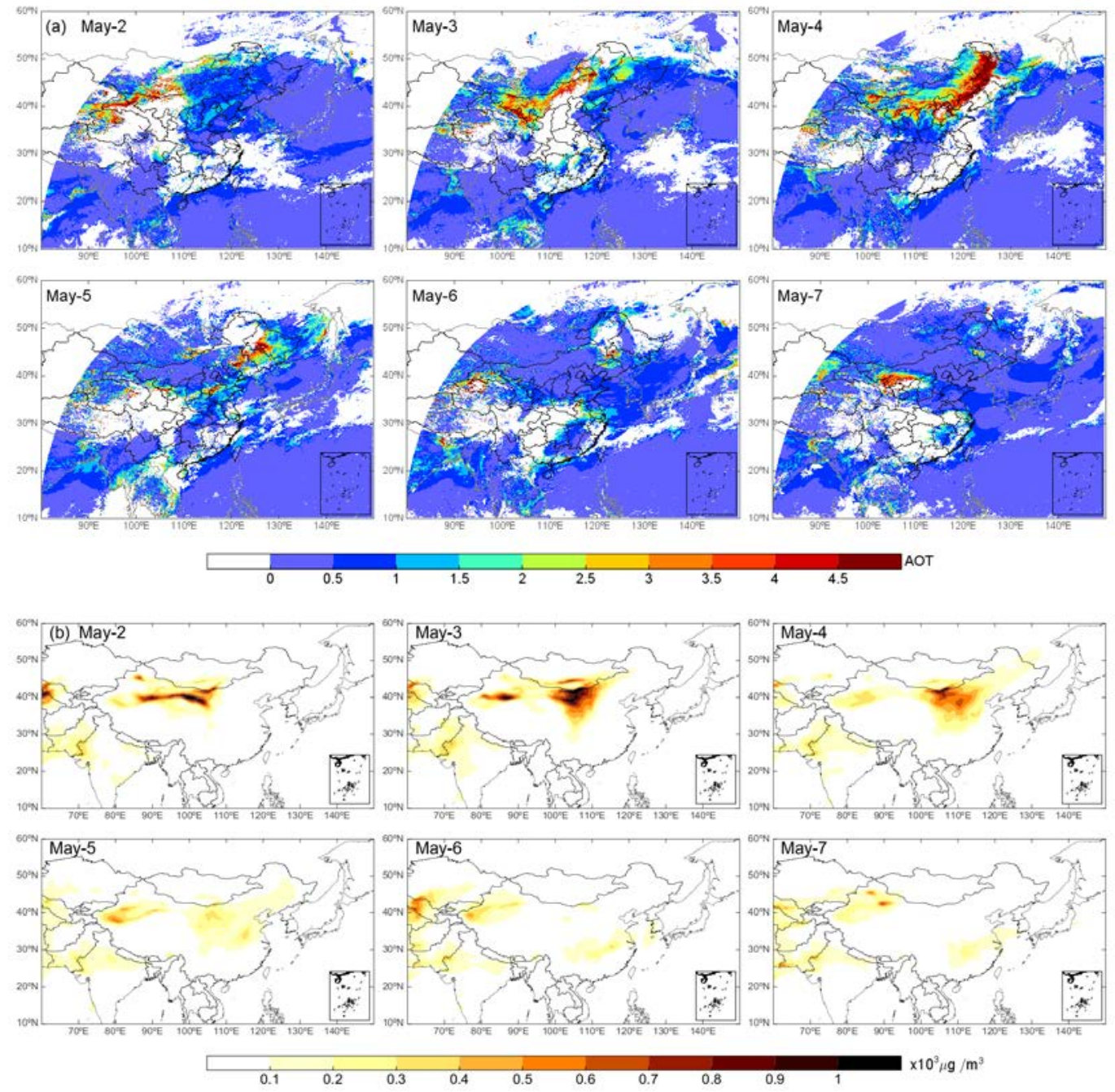

Figure 2. (a) Spatial distribution of the AOT (Himawari-8) on 2-7 May 2017; (b) spatial distribution of the dust column mass concentration (MERRA-2) on 2-7 May 2017.

There was a dust event in the Taklimakan Desert on 2 May 2017 and the dust traveled eastward, influencing western and central Inner Mongolia and the southern border of Mongolia. A new dust emission occurred in the Gobi Desert on 3 May 2017, increasing the mass concentration of dust. The dust traveled east, north, and south, affecting northern and central China. On 4 May, the dust was transmitted east, northeast, and south, further affecting north, central, east, and northeast China. The dust traveled further on 5 and 7 May and affected the ocean and Japan. Further dust events occurred in the Taklimakan Desert from May 3 to 7 and emitted a large amount of dust, although this only affected the local weather conditions and no long-distance transport occurred (Figure 2).

Analysis of the data from representative stations on the dust transport path indicated that the $\mathrm{PM}_{10}$ concentration of each station fluctuated substantially in the direction of dust transport. This is consistent with the spatiotemporal distribution of the dust described by the MERRA-2 data. The $\mathrm{PM}_{2.5}$ concentration in some cities fluctuated during the period affected by dust, with significant fluctuations 
in Baotou and Beijing and significant small fluctuations in Yinchuan and Xilin Gol League. Dust deposition affected the concentration of aerosols in the lower atmosphere. The mixing of dust and aerosols in the lower atmosphere aggravates pollution and the deposition of fine particles in the dust will directly increase the concentration of $\mathrm{PM}_{2.5}$ (Figure 3). The concentration of $\mathrm{PM}_{10}$ in Hetian was affected by the dust event in the Taklimakan Desert and fluctuated on 2-8 May 2017 and there are maximal values on 3-5 May 2017. There were different amplitude fluctuations of $\mathrm{PM}_{10}$ in Korla on 3-8 May 2017, with the strongest fluctuations on 3 May, followed by the fluctuations on 7 May.

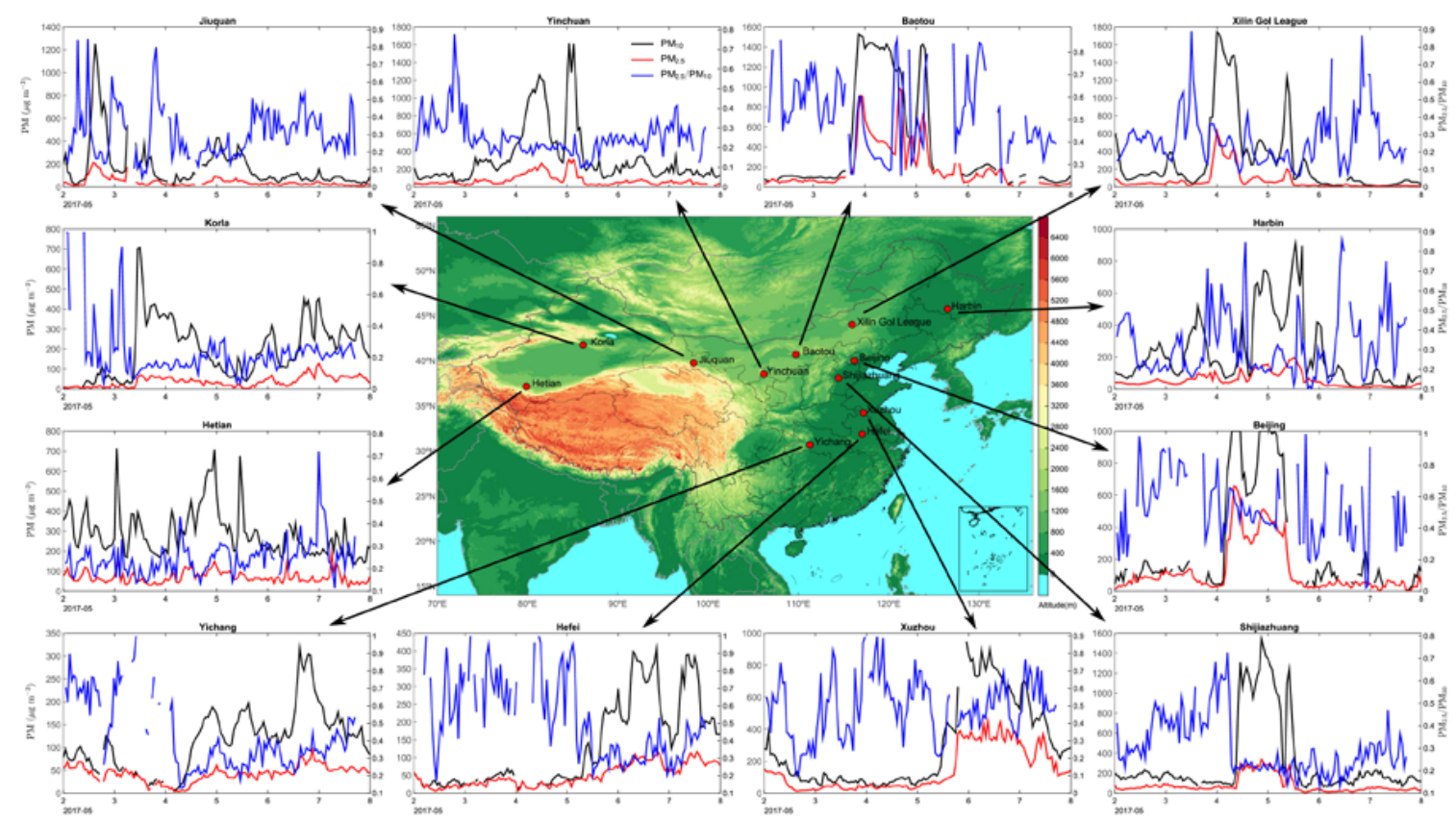

Figure 3. Hourly average spatial distribution of $\mathrm{PM}_{2.5}, \mathrm{PM}_{10}$, and $\mathrm{PM}_{2.5} / \mathrm{PM}_{10}$ at 12 typical stations on 2-7 May 2017.

The $\mathrm{PM}_{10}$ concentration at Yinchuan station fluctuated greatly on 4 and 5 May, whereas the $\mathrm{PM}_{2.5}$ concentration only fluctuated slightly. There was a large fluctuation at Baotou station on 3-5 May. The $\mathrm{PM}_{2.5}$ concentration fluctuated almost simultaneously with the $\mathrm{PM}_{10}$ concentration in Baotou, Beijing and Xuzhou, and was slightly less than the $\mathrm{PM}_{10}$ concentration. Beijing station showed a large fluctuation on 4-6 May. Xilin Gol League station showed a large fluctuation in the $\mathrm{PM}_{10}$ concentration on 3-5 May with a maximum of $1800 \mu \mathrm{g} / \mathrm{m}^{3}$, accompanied by a small fluctuation in the $\mathrm{PM}_{2.5}$ concentration. The concentration of $\mathrm{PM}_{10}$ at Harbin station fluctuated slightly on 3 May and fluctuated greatly on 5 May, but there was little fluctuation in the $\mathrm{PM}_{2.5}$ concentration. There were large fluctuations at Shijiazhuang station on 4 and 5 May, with small, significant fluctuations in $\mathrm{PM}_{2.5}$. Xuzhou station showed a large fluctuation on 5-7 May 2017. There were large fluctuations of $\mathrm{PM}_{10}$ at Hefei station on 5-7 May and small, significant fluctuations in $\mathrm{PM}_{2.5}$. $\mathrm{PM}_{10}$ in Yichang station showed a clear fluctuation from May 4 to 7 and the largest fluctuation on 6 May, the $\mathrm{PM}_{2.5}$ concentration showed a clear small fluctuation.

We selected the hourly average AOD data from Baotou, Beijing, Xuzhou, Ussuriysk, and Gwangju_GIST to verify the accuracy of the MERRA-2 AOD data. Figure 4 shows that the change trend of the AOD shown by the MERRA-2 and AERONET data were basically consistent. The AOD was greatly affected by coarse mode aerosol particles and the peak of the AOD in Baotou, Beijing, and Xuzhou is clearly distributed before and after the dust event. The AOD in Ussuriysk and Gwangju GIST also fluctuated significantly when dust is transmitted to the local area. The observed values at the stations further confirm the transport direction of the dust from west to east and the distribution of dust obtained based on Figure 2. 

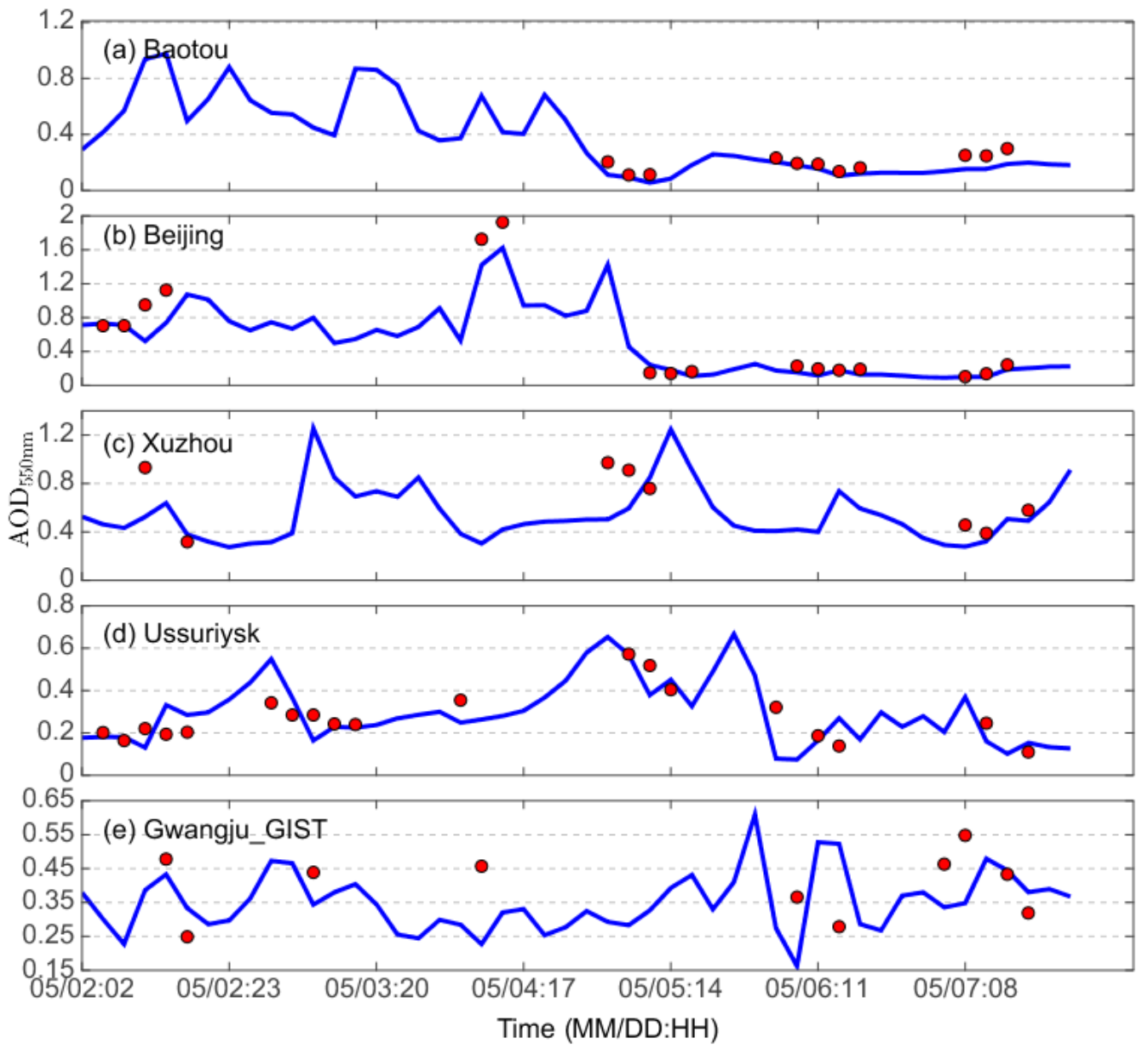

Figure 4. Hourly average spatial distribution of the AOD at five typical AERONET stations during the period 2-7 May 2017 (Beijing time). The red dots represent the AERONET hourly average AOD and the blue curve represents the MERRA-2 AOD. (sub-graph (a-e) respectively describe the hourly average spatial distribution of the AOD at Baotou, Beijing, Xuzhou, Ussuriysk, and Gwangju_GIST)

According to this analysis, the transport of dust during this event in the east, south, and northeast directions affected the northwestern China, northern China, central China, northeastern China, and the east coast of China. The spatiotemporal distribution of dust described by the MERRA-2 data is consistent with the data from Himawari-8, AERONET and the national urban air quality publishing platform (Figures S2 and S3). This indicates that the MERRA-2 data can accurately describe the dust process and capture the variations of dust characteristics.

\subsection{Vertical Evolution of Dust}

According to our analysis of the aerosol distribution profile on the CALIPSO observation track on 2-7 May 2017 (Figure 5a,b), the vertical range of influence of the dust was from 1 to $10 \mathrm{~km}$. The dust event occurred in the Taklimakan Desert on 2 May and the dust spread from east to south and influenced the western region of Inner Mongolia on 3 May and northern and central China on 4 May. Combining with the MERRA-2 data (Figure 6) to analyze the vertical distribution of dust from a three-dimensional perspective. The vertical area of influence of dust on 4 May reached an altitude of $10 \mathrm{~km}$ and affected most of northern China, northwest, north, central, east, and northeast China, and the eastern coastal areas. A small amount of dust was transferred to the ocean and the region of Japan. The dust affected northeast China, east China, southeast China, the Huanghai Sea, and the Bohai Sea on 5 May and spread to the Sea of Japan and the Sea of Okhotsk and affected Japan on 6 May. The vertical aerosol extinction profile in Figure $5 \mathrm{~b}$ shows that dust events affected an altitude of about $10 \mathrm{~km}$ above 
surface. The amount of dust fluctuated greatly at $0-2 \mathrm{~km}$, but only slightly at $2-6 \mathrm{~km}$. The amplitude of fluctuation was smaller at greater heights.
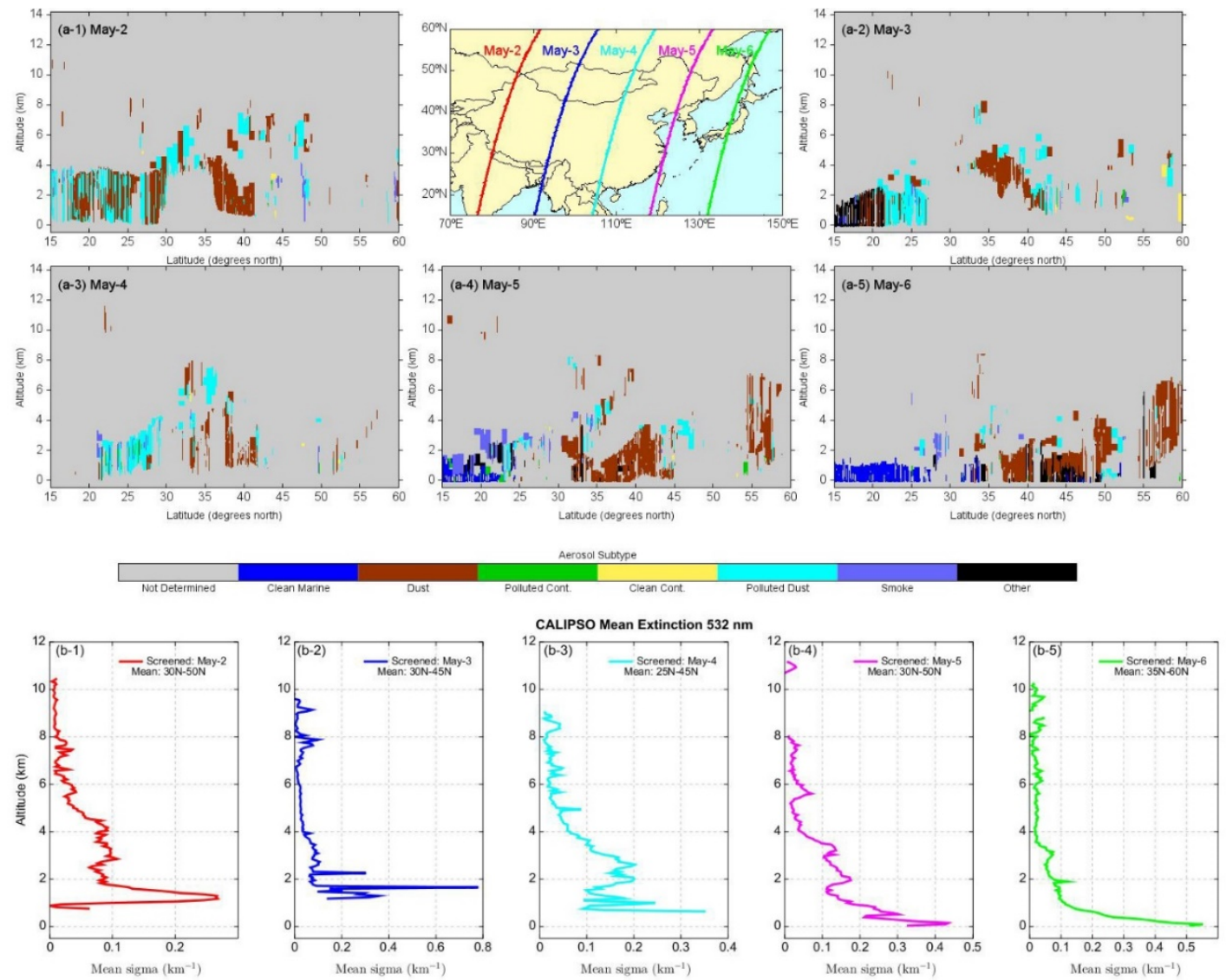

Figure 5. (a) Vertical profiles of daily aerosol types on the CALIPSO observation track on 2-6 May 2017. (b) Vertical profiles of the mean aerosol extinction coefficient on the CALIPSO observation track on 2-6 May 2017. Different colors represent the observed track on different dates (nighttime observation).

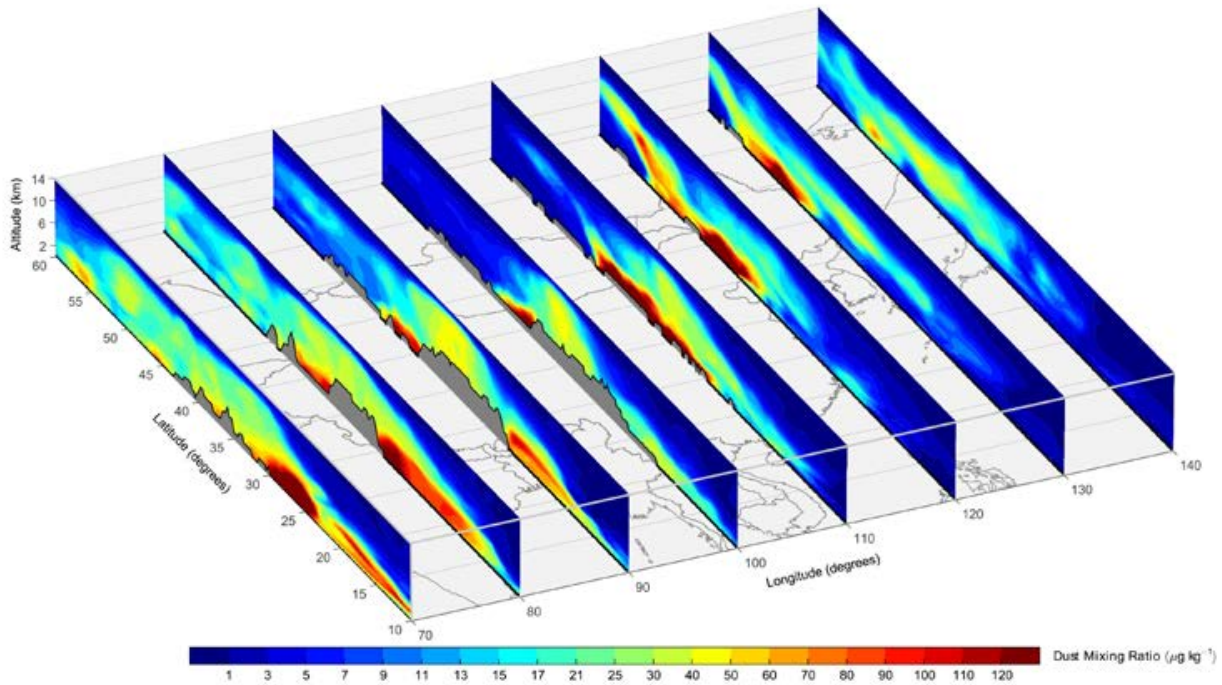

Figure 6. Three-dimensional vertical profiles of the all-bins dust aerosol mixing ratio on 4 May 2017.

The vertical distribution of dust at typical affected stations was further analyzed using Lidar data (Figure 7). The lidar stations in Inner Mongolia was affected by dust from 0 to $6 \mathrm{~km}$ above the ground 
on 3-5 May 2017 with a depolarization ratio of up to 0.3 in most time periods. The maximum extinction coefficient was at about $0.1 \mathrm{~km}$ with a value of $0.23 / \mathrm{km}$ and the maximal value was about $0.13 / \mathrm{km}$ at $2 \mathrm{~km}$ on 3 May. As a result of the vertical movement of the atmosphere and the transport and deposition of dust, the area of influence of the dust gradually extended to the upper levels on 4-5 May 2017 and the influence at lower levels gradually weakened. On 4 May, the maximum extinction coefficient was about $0.165 / \mathrm{km}$ at $0.1 \mathrm{~km}$ and the maximal value was about $0.15 / \mathrm{km}$ at $1.8 \mathrm{~km}$. On 5 May, the maximum extinction coefficient was about $0.075 / \mathrm{km}$ at $5 \mathrm{~km}$ with a maximal value of about $0.07 / \mathrm{km}$ at $2.3 \mathrm{~km}$. Comparing the results of the analysis of the satellite and lidar data with Figures 2 and 6, we found that the description of the distribution of dust by the MERRA-2 data was consistent with the satellite and lidar observational data.
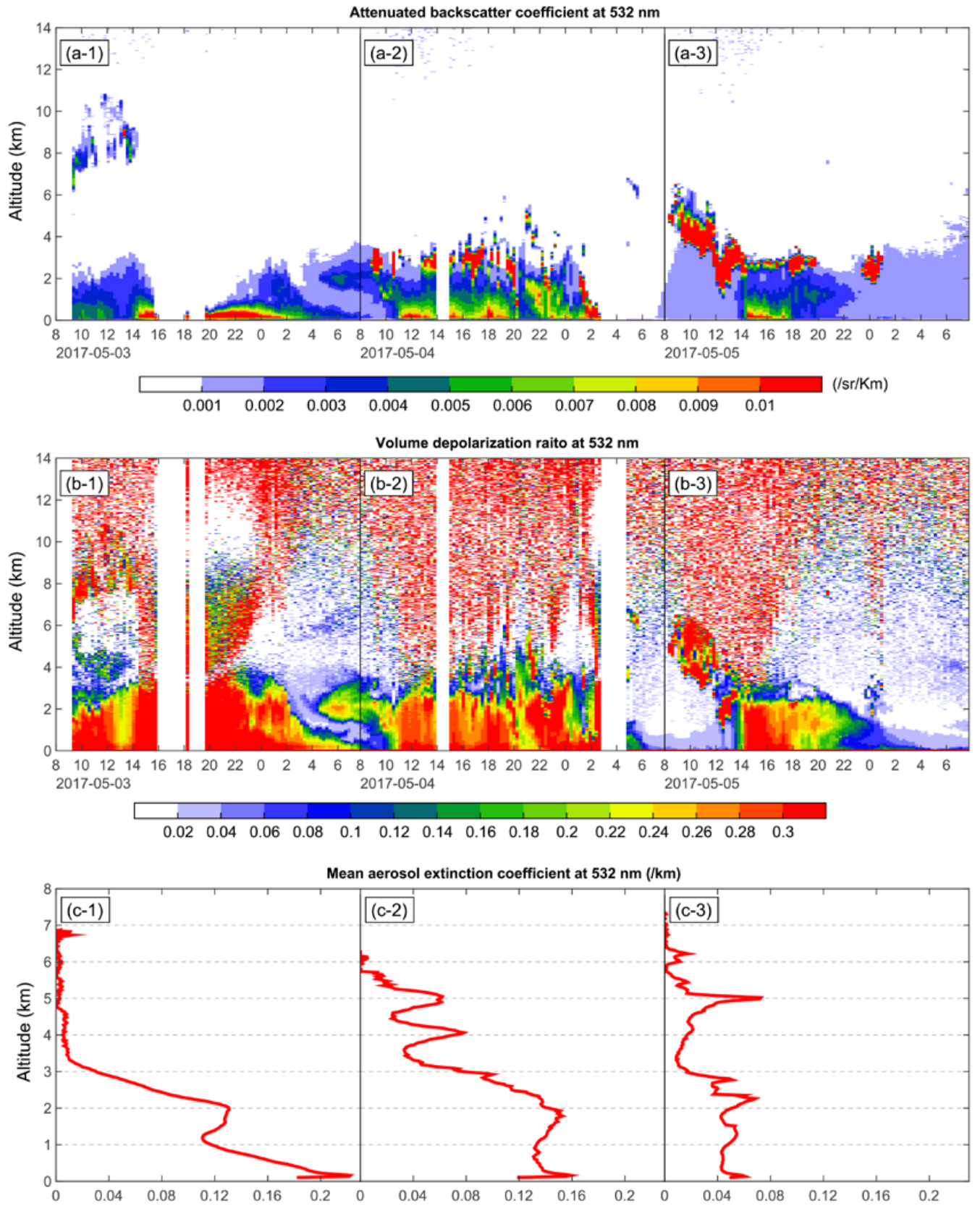

Figure 7. Variation of aerosol parameters measured by Lidar in Inner Mongolia on 3-5 May 2017. $((\mathbf{a}-\mathbf{1})$ to $(\mathbf{a}-\mathbf{3}),(\mathbf{b}-\mathbf{1})$ to $(\mathbf{b}-\mathbf{3})$ and (c-1) to (c-3) respectively describe the attenuated backscatter coefficient, volume depolarization ratio and mean aerosol extinction coefficient at $532 \mathrm{~nm}$ on 3-5 May 2017) 


\subsection{Meteorological Conditions}

Previous studies have shown that the emission and transport of dust are closely related to circulation factor drivers in both observations and models [15,37,38]. Therefore, the MERRA-2 wind field data were selected to analyze the circulation driving factors of dust events.

By comparing the vertical motion in the atmosphere during the dust event (Figure 8) with the mixing ratio of dust aerosols (Figure 9), it can be seen that the areas affected by dust during the dust event on 2-7 May, especially the areas with a high mixing ratio of dust aerosols, had better vertical transport conditions from the ground to about $10 \mathrm{~km}$ above sea-level, which lifted the dust to the upper atmosphere. The high-value zone of the dust aerosol mixing ratio and the high-value zone of rising movement existed simultaneously at $90-110^{\circ} \mathrm{E}$ on 2 May, between 110 and $120^{\circ} \mathrm{E}$ on 3 May and between 120 and $130^{\circ} \mathrm{E}$ on 4 May. There was also a small vertical transport of dust between 130 and $140^{\circ} \mathrm{E}$ on 6 May. The vertical transport was weak on 7 May. Good vertical transport combined with the high winds near the trough led to the long-distance transport of dust at high altitudes. The sinking motion in other areas favored deposition.

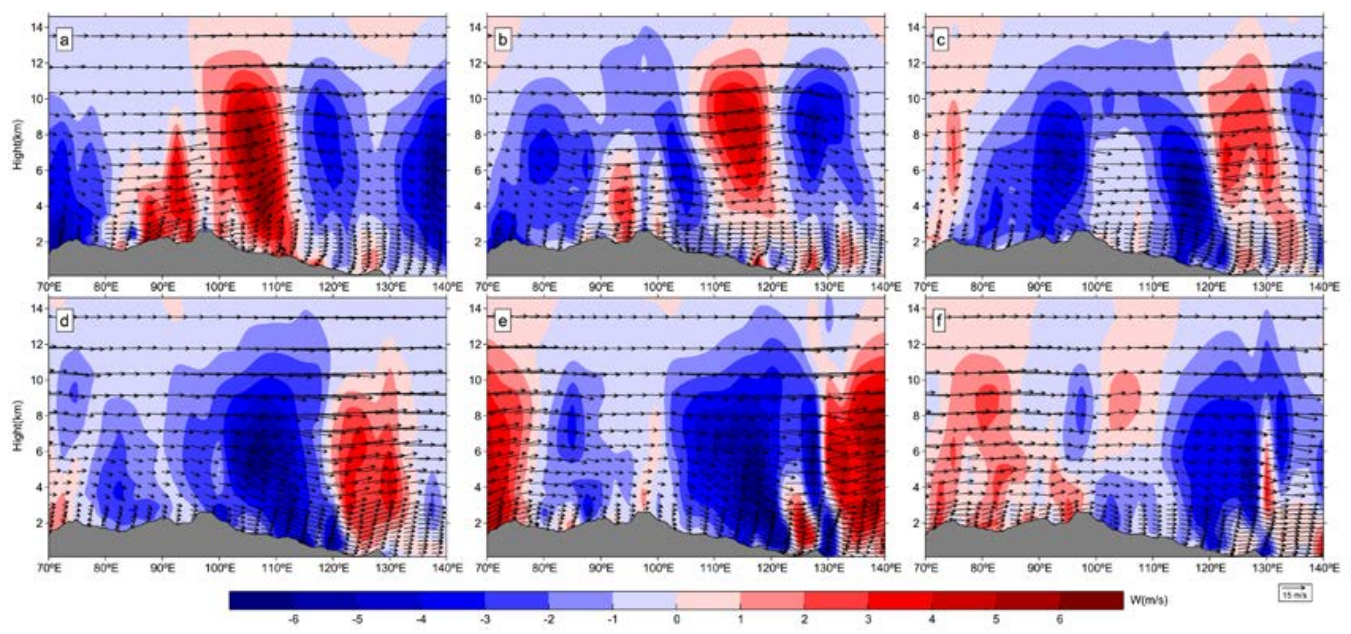

Figure 8. Vertical profile of the whole-layer MERRA-2 wind field on 2-7 May (shaded area represents the $\mathrm{W}$ wind; to show more clearly, $\mathrm{W}=-30 \mathrm{~W}$ in the figure; blue indicates vertical downward movement and red indicates upward vertical movement, sub-graph $(\mathbf{a}-\mathbf{f})$ respectively describe the wind field on 2-7 May 2017).
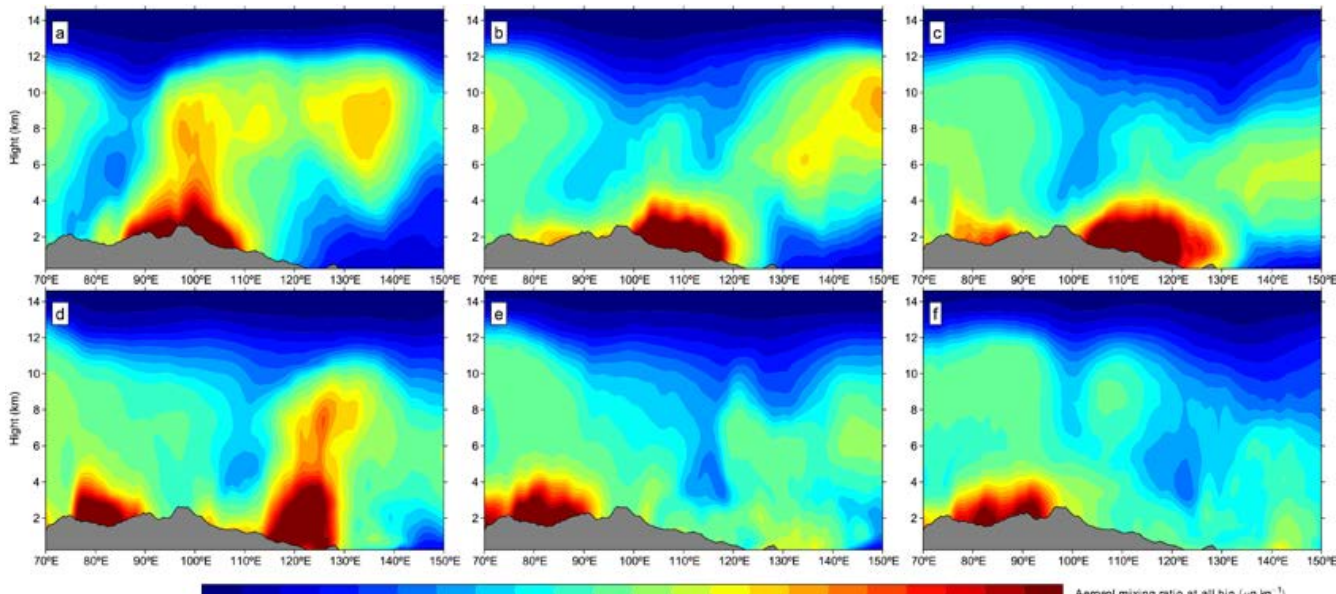

Figure 9. Vertical profile of dust aerosol mixing ratio of all bins accumulated in the atmosphere on a single day on 2-7 May 2017(sub-graph (a-f) respectively describe the dust aerosol mixing ratio on 2-7 May 2017). 
Under the influence of the overall westerly wind direction, the dust always shows a trend of eastward transport. There was a cold low-pressure trough at $500 \mathrm{hPa}$ on 2 May 2017. The bottom of the trough extended to southern Xinjiang and there was a strong northwesterly wind behind the trough and a southwesterly wind in front of the trough. The strong wind in front of the trough drove the dust in the upper air to the east and north, affecting central and western Inner Mongolia and southern Mongolia. The low-pressure trough then developed and moved eastward. The wind in front of the trough affected Inner Mongolia on 3 May, continuing to transport the dust eastward. In combination with the emission and vertical transport of dust in the Gobi Desert on 3 May, this eastward movement further developed the scale of the dust event. The low-pressure trough continued to move east on 4-7 May, driving the transport of dust. The northwesterly wind behind the trough caused the high-altitude dust behind the trough to travel east and south, gradually affecting north, central, and south China. The eastern coastal areas were also affected with the development and movement of the trough and the dust. The southwesterly wind in front of the trough caused the dust to travel northeast, gradually affecting northeast China, Korea, and Japan and the adjacent ocean area (Figure 10). The cold advection behind the trough was conducive to a sinking motion and deposition, whereas the warm advection in front of the trough was conducive to ascending motion and the uplift of dust.
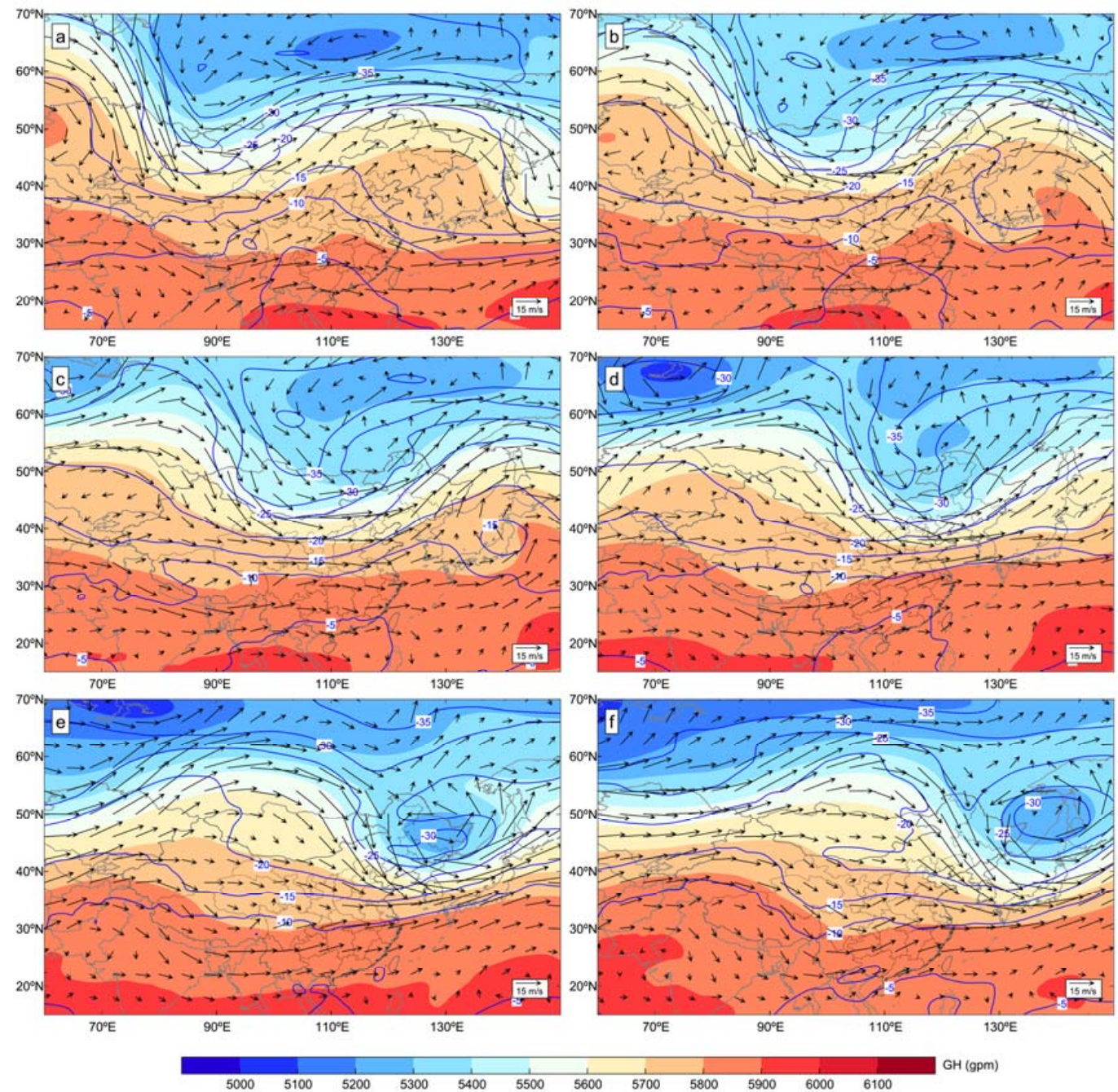

Figure 10. Spatiotemporal variation of the geopotential height (shaded), wind field and temperature (contours) at $500 \mathrm{hPa}$ on 2-7 May 2017(sub-graph (a-f) respectively describe the geopotential height, wind field and temperature at $500 \mathrm{hPa}$ on 2-7 May 2017). 
A cold low-pressure trough gradually developed and moved eastward at $850 \mathrm{hPa}$ and the cold air moved southward, developing and strengthening the trough. The northwesterly wind was behind the trough and the southwesterly wind was in front of the trough. The overall wind direction transferred the dust to the east and the wind speed was less than that at $500 \mathrm{hPa}$. The northwesterly wind behind the trough transported the low-altitude dust from east to south, whereas the southwesterly wind in front of the trough transported the dust to the northeast, which had a great influence on the air quality (Figure 11).
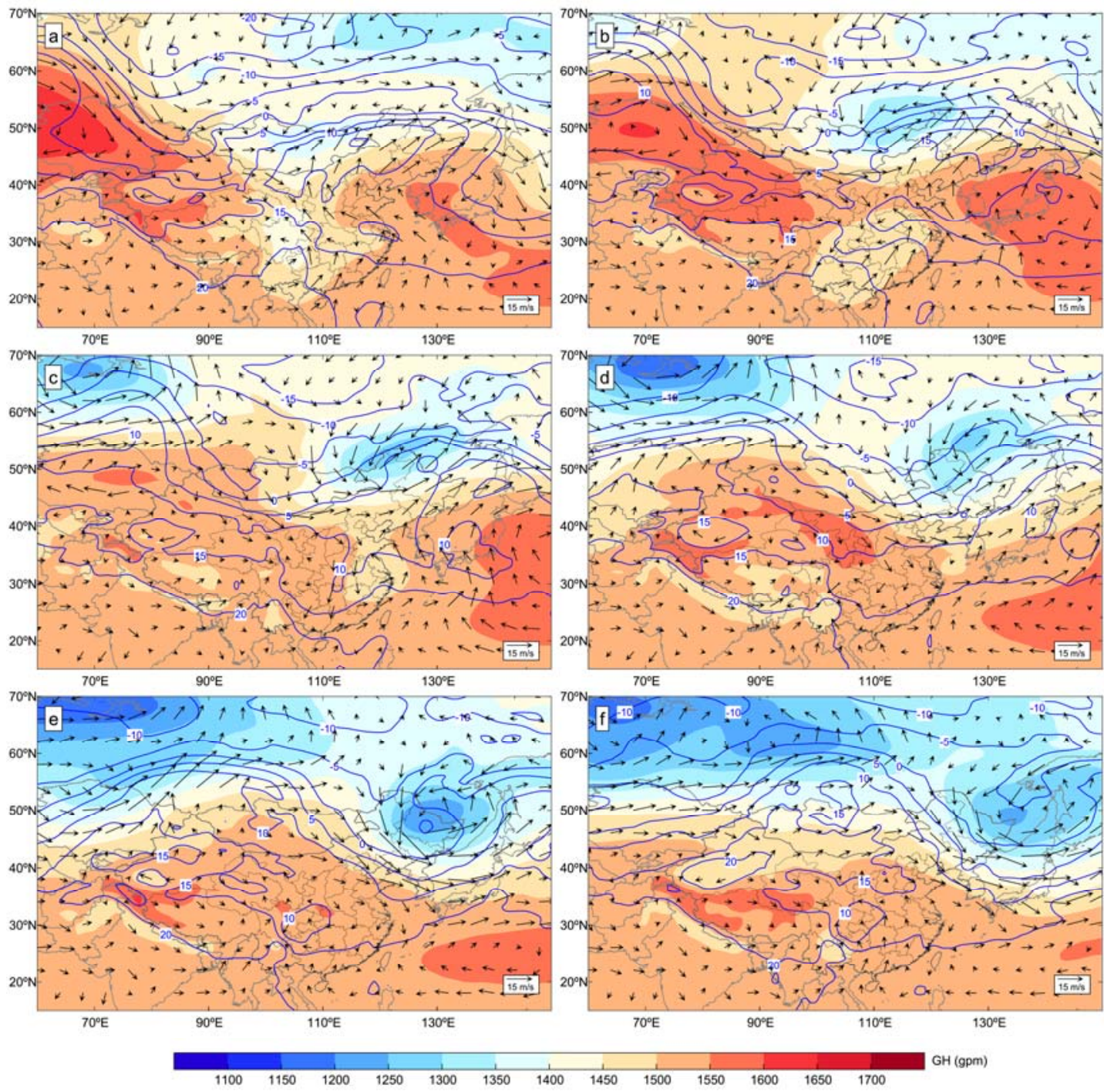

Figure 11. Variation of the geopotential height (shading), wind field and temperature (contours) at 850 hPa on 2-7 May 2017(sub-graph (a-f) respectively describe the geopotential height, wind field and temperature at $850 \mathrm{hPa}$ on 2-7 May 2017).

\subsection{Dust Budget Analysis}

As a result of the assimilation of various aerosol observations, the MERRA-2 data have many advantages in the estimation and analysis of the dust load, emission and deposition in severe dust events and is an effective tool for the quantitative estimation of the dust balance in extreme dust events [39-41]. To understand the dust budget, we used the MERRA-2 reanalysis data to analyze the emission and the dry and wet deposition of dust in this dust event.

The main emission sources of the dust are the Taklimakan and Gobi deserts. The highest emission of dust was concentrated on 2-4 May and was mainly in the Gobi Desert, with the maximum value 
reaching $1.9 \times 10^{6} \mu \mathrm{g} / \mathrm{m}^{3}$ (Figure 12). The emission of dust in the Taklimakan Desert was also high on 2 May, with the maximum value reaching $1.8 \times 10^{6} \mu \mathrm{g} / \mathrm{m}^{3}$. There was a small amount of dust emission from the Gobi Desert on 5 May, which affected the dust event. The Taklimakan Desert released a small amount of dust on 3-6 May, but, as a result of the unfavorable terrain of the basin and the prevailing easterly wind, the emission only affected the surrounding areas and was difficult to transport eastward [6,42]. A comparison of the mixing ratios of different particle sizes in the dust process indicated that the effective radius of dust emitted in this process was mainly 1.4-2.4 $\mu \mathrm{m}$ (Figure S4-S8). Kenji Kai et al. (2019) found the dust emission in the Khorchin sandy land during the dust event by analyzing both the data and Himawari-8 Dust RGB imagery [24], but the MERRA-2 data did not capture the emission process. Although the MERRA-2 dataset could capture the characteristics of the event, it was still insufficient for the emission of dust.
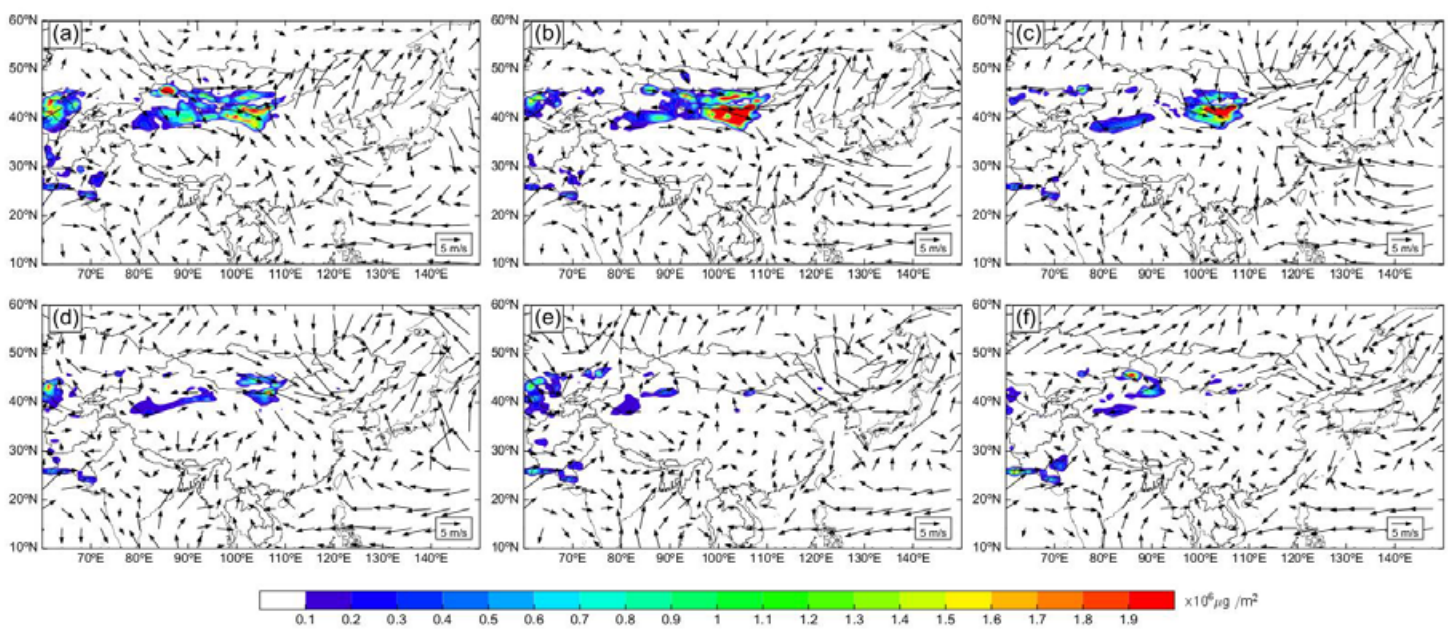

Figure 12. Spatial distribution of dust aerosol emission on 2-7 May 2017. The wind field is $10 \mathrm{~m}$ above the ground. (sub-graph (a-f) respectively describe dust aerosol emission on 2-7 May 2017)

The large-value area of dry deposition of dust is consistent with the transport and area of influence of dust. On 2-5 May, the deposition of dust mainly occurred in the Taklimakan Desert and the western part of Inner Mongolia, the Gobi Desert, north China, central China, south China, northeast and east China, and the eastern coast. There was a maximum deposition of $9 \times 10^{4} \mu \mathrm{g} / \mathrm{m}^{3}$ on 3 and 4 May. Dry deposition on 6 and 7 May mainly occurred in the Taklimakan Desert and south China (Figure 13).
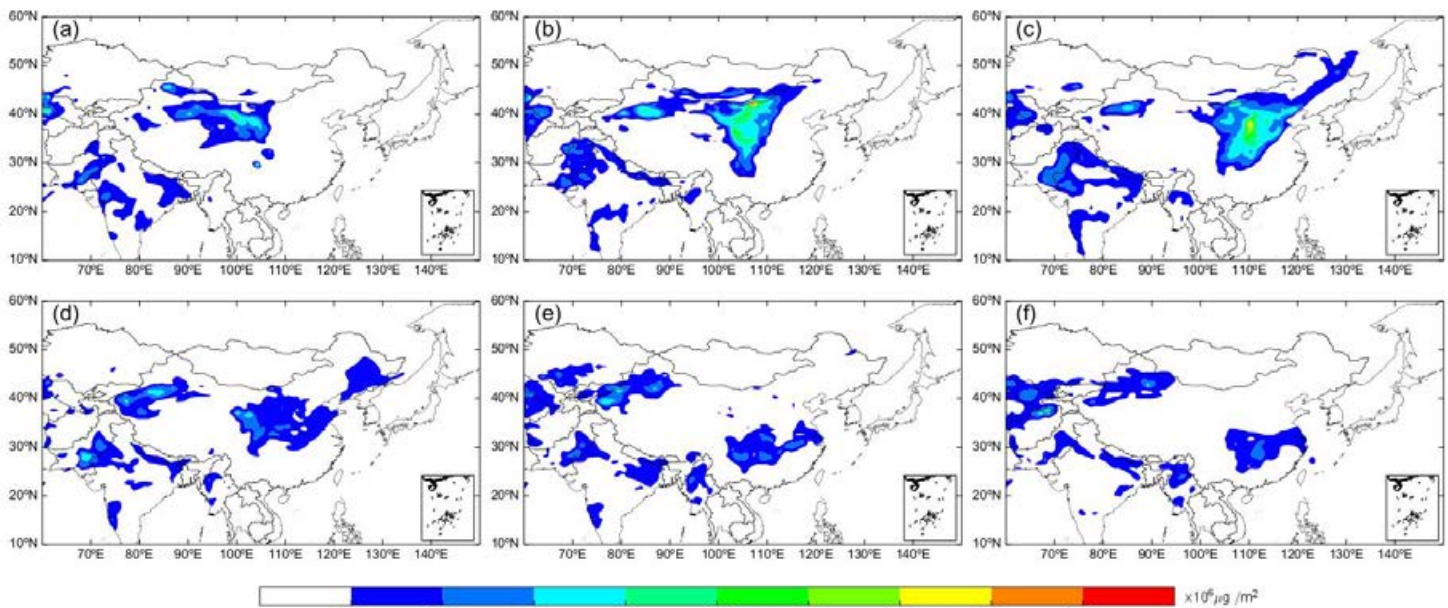

Figure 13. Spatial distribution of daily dust aerosol dry deposition on 2-7 May 2017(sub-graph (a-f) respectively describe dust aerosol dry deposition on 2-7 May 2017). 
In contrast with the dry deposition, wet deposition was larger in magnitude and occurred in most areas. Wet deposition occurred on 2-7 May in the Taklimakan Desert, western Inner Mongolia, the Gobi Desert, north China, central China, east China, south China, northeast China, the southeast coast, Japan, and the adjacent sea areas. Among the affected areas of this event, the high value areas of high wet deposition are distributed in northwest China, north China, and central China on 2 May. There were high-value areas in central and eastern China on $3 \mathrm{May}$, a small amount of wet deposition in northeast and central China on 4 May, high-value areas in northeast China on 5 and 6 May, areas of wet deposition in the ocean and Japan on 6 May and a high-value area in the central and southeastern coastal areas on 7 May, with the highest value reaching $2 \times 10^{5} \mu \mathrm{g} / \mathrm{m}^{3}$ (Figure 14).
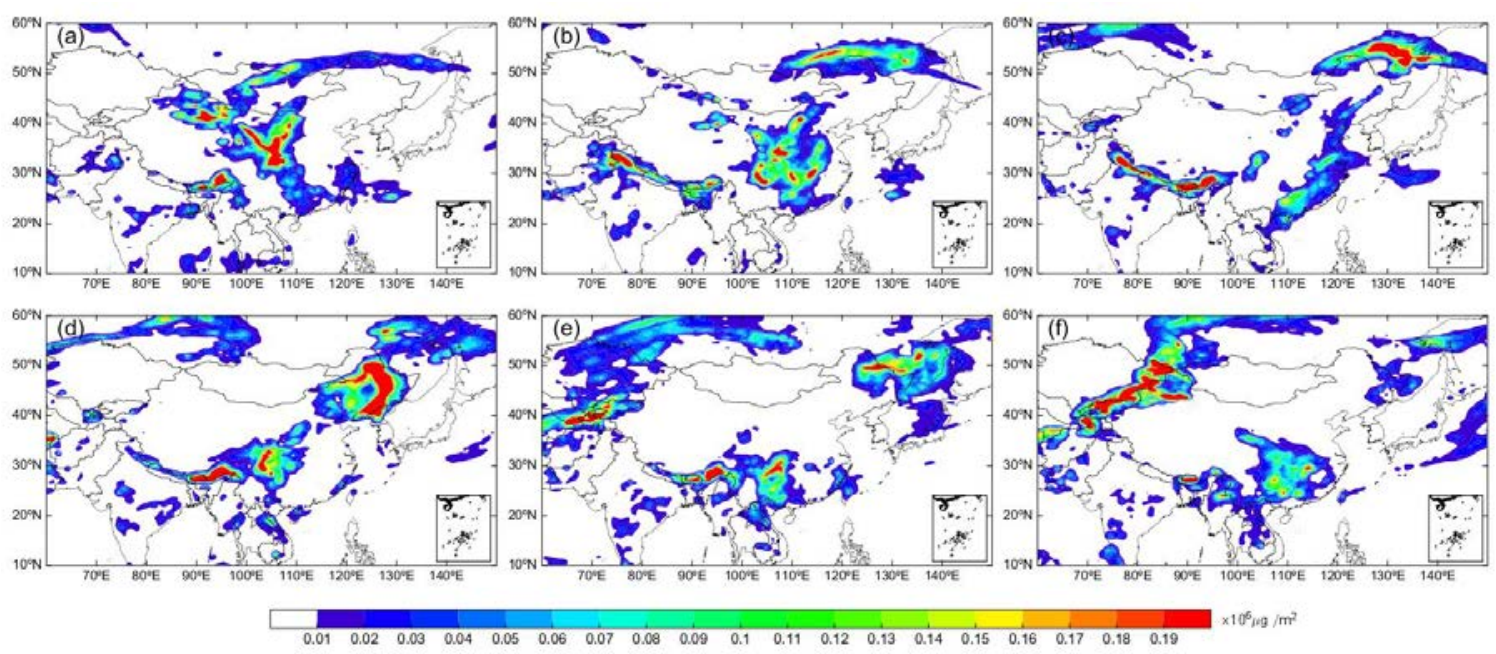

Figure 14. Spatial distribution of daily dust aerosol wet deposition on 2-7 May 2017(sub-graph (a-f) respectively describe dust aerosol wet deposition on 2-7 May 2017).

\section{Conclusions}

We used MERRA-2 reanalysis data, ground-based data, and satellite observational data to analyze the strong dust event that occurred in east Asia on 2-7 May 2017. We evaluated the accuracy of the MERRA-2 reanalysis data in the simulation of the dust event, analyzed the spatiotemporal distribution, vertical evolution and background circulation conditions of the dust aerosols, and considered the dust budget.

The Taklimakan and Gobi deserts were the two sources of dust in this event, with the Gobi Desert as the main source area. Although there were multiple emissions from the Taklimakan Desert, the dust was rarely transported and did not affect other areas after 2 May. Most of the dust from the Taklimakan Desert was deposited during transport. The emission of dust from the Gobi Desert on 3-5 May increased the intensity and scale of the dust event, which affected most of China, Korea, Japan and adjacent sea areas, for up to six days. The results of comparison show that the description of the spatiotemporal distribution and evolution of the dust aerosols in the dust event using the MERRA-2 model is consistent with the data of AERONET, National Urban Air Quality Real-time Publishing Platform and Hamawari-8.

Analysis of the atmospheric circulation showed that the transport of dust was mainly affected by the low-pressure trough at 500 and $850 \mathrm{hPa}$ and the vertical movement of the atmosphere. The dust was high-altitude long-distance transported, with a vertical influence range up to $10 \mathrm{~km}$ in the upper atmosphere. There were always better conditions for vertical transport in the area affected by dust and the vertical motion of the atmosphere transported dust to altitudes $>500 \mathrm{hPa}$. There was a low-pressure trough at 500 and $850 \mathrm{hPa}$ and this trough continued to develop eastward. The northwesterly wind behind the trough and the southwesterly wind in front of the trough drove the dust behind the trough to move eastward and southward and the dust in front of the trough to move northeast. The dust from 
the ground to the upper atmosphere continued to travel east, south, and northeast, affected northwest China, north China, northeast China, the southeastern coast, the ocean and Japan in turn.

Dust was deposited in the Taklimakan Desert and western Inner Mongolia, the Gobi Desert, north China, central China, south China, northeast China and east China, as well as on the eastern coast. Dry deposition on 6 and 7 May mainly occurred in the Taklimakan Desert and south China. There was a maximum deposition of $9 \times 10^{4} \mu \mathrm{g} / \mathrm{m}^{3}$ on 3 and 4 May. The wet deposition was larger in magnitude and occurred more widely than the dry deposition. Among the affected areas of this event, the high value areas of high wet deposition are distributed in northwest China, north China, and central China on 2 May. There were high-value areas in central and eastern China on 3 May, a small amount of wet deposition in northeast and central China on 4 May, high-value areas in northeast China on 5 and 6 May, areas of wet deposition in the ocean and Japan on 6 May and a high-value area in the central and southeastern coastal areas on 7 May, with the highest value reaching $2 \times 10^{5} \mu \mathrm{g} / \mathrm{m}^{3}$. The MERRA-2 data did not capture the dust emission in the Khorchin area during this event, which indicates that the emission source of the MERRA-2 model was uncertain and needs to be improved.

The comparison with satellite and ground-based observational data indicates that the MERRA-2 model can accurately reproduce the dust evolution process, including the spatial distribution and three-dimensional vertical distribution of dust aerosols. Although there are a few inadequacies in the accuracy of the data (such as the uncertainty about the dust source) in MERRA-2 reanalysis data, it has a three-dimensional perspective and comprehensive data, which can describe the evolution of dust events, reproduce the dust process. The MERRA-2 data can be used to analyze dust events comprehensively from the three-dimensional spatiotemporal distribution characteristics, circulation driving factors and dust budget. But the accuracy of the MERRA-2 data in simulating the long-term evolution of dust aerosols requires further evaluation.

Supplementary Materials: The following are available online at http://www.mdpi.com/2072-4292/12/6/902/s1. Figure S1: Spatial distribution of the surface mass concentration of dust on 2-7 May 2017. (sub-graph (a) to (f) respectively describe the surface mass concentration of dust on 2-7 May 2017) Figure S2: Daily average spatial distribution characteristics of $\mathrm{PM}_{10}$ on 2-7 May 2017 (Beijing time). (sub-graph (a) to (f) respectively describe daily average spatial distribution characteristics of $\mathrm{PM}_{10}$ on 2-7 May 2017) Figure S3: Daily average spatial distribution characteristics of $\mathrm{PM}_{2.5} / \mathrm{PM}_{10}$ on 2-7 May 2017 (Beijing time). (sub-graph (a) to (f) respectively describe daily average spatial distribution characteristics of $\mathrm{PM}_{2.5} / \mathrm{PM}_{10}$ on 2-7 May 2017) Figure S4: Vertical profile of dust aerosol mixing ratio of bin-001 accumulated in the atmosphere on a single day on 2-7 May 2017. (sub-graph (a) to (f) respectively describe dust aerosol mixing ratio of bin-001 on 2-7 May 2017) Figure S5: Vertical profile characteristics of dust aerosol mixing ratio of bin-002 accumulated in the atmosphere on a single day on 2-7 May 2017. (sub-graph (a) to (f) respectively describe dust aerosol mixing ratio of bin-002 on 2-7 May 2017) Figure S6: Vertical profile characteristics of dust aerosol mixing ratio of bin-003 accumulated in the atmosphere on a single day on 2-7 May 2017. (sub-graph (a) to (f) respectively describe dust aerosol mixing ratio of bin-003 on 2-7 May 2017) Figure S7: Vertical profile characteristics of dust aerosol mixing ratio of bin-004 accumulated in the atmosphere on a single day on 2-7 May 2017. (sub-graph (a) to (f) respectively describe dust aerosol mixing ratio of bin-004 on 2-7 May 2017) Figure S8: Vertical profile characteristics of dust aerosol mixing ratio of bin-005 accumulated in the atmosphere on a single day on 2-7 May 2017. (sub-graph (a) to (f) respectively describe dust aerosol mixing ratio of bin-005 on 2-7 May 2017)

Author Contributions: H.C., K.G., W.Y. contributed to designing the research content, processing data, analyzing the results, visualizing the results, writing review and editing the manuscript; Y.W. provide the Drawing software; X.Z. provided useful advice for this study. All authors have read and agreed to the published version of the manuscript.

Funding: Funding: This work was supported by grant from The National Science Fund for Distinguished Young Scholars (41825011), the National Key R \& D Program Pilot Projects of China (2016YFA0601901) and the CAMS Basis Research Project (2017Z011).

Acknowledgments: We would like to thank the following agencies for providing data: The MERRA-2 reanalysis data are managed by the NASA Goddard Earth Sciences (GES) Data and Information Services Center (DISC) (https://gmao.gsfc.nasa.gov/reanalysis/MERRA-2/data_access/). The aerosol products are provided by AERONET networks (https://aeronet.gsfc.nasa.gov/), CALIPSO (https://www-calipso.larc.nasa.gov/resources/bibliographies. php) and AD-net (http://www-lidar.nies.go.jp/AD-Net/). Research product of aerosol properties (produced from Himawari-8) was derived by the algorithm developed by Japan Aerospace Exploration Agency (JAXA) and National Institute of Environmental Studies (NIES). PM $_{10}$ data is provided by national urban air quality publishing platform (http://106.37.208.233:20035). 
Conflicts of Interest: The authors declare no conflict of interest.

\section{References}

1. Cakmur, R.V.; Miller, R.L.; Perlwitz, J.; Geogdzhayev, I.V.; Ginoux, P.; Koch, D.; Kohfeld, K.E.; Tegen, I.; Zender, C.S. Constraining the magnitude of the global dust cycle by minimizing the difference between a model and observations. J. Geophys. Res. 2006, 111, D06207. [CrossRef]

2. Zhou, M.; Chen, Z.; Huang, R.; Wang, Q.; Arimoto, R.; Parungo, F.; Lenschow, D.H.; Okada, K.; Wu, P. Effects of two dust storms on solar radiation in the Beijing-Tianjin area. Geophys. Res. Lett. 1994, 21, 2697-2700. [CrossRef]

3. Che, H.; Xia, X.; Zhao, H.; Dubovik, O.; Holben, B.N.; Goloub, P.; Cuevas-Agulló, E.; Estelles, V.; Wang, Y.; $\mathrm{Zhu}$, J.; et al. Spatial distribution of aerosol microphysical and optical properties and direct radiative effect from the China aerosol remote sensing network. Atmos. Chem. Phys. 2019, 19, 11843-11864. [CrossRef]

4. Zhang, C.; Liu, C.; Hu, Q.; Cai, Z.; Su, W.; Xia, C.; Zhu, Y.; Wang, S.; Liu, J. Satellite UV-Vis spectroscopy: Implications for air quality trends and their driving forces in China during 2005-2017. Light Sci. Appl. 2019, 8, 100. [CrossRef]

5. Gui, K.; Che, H.; Chen, Q.; Zeng, Z.; Zheng, Y.; Long, Q.; Sun, T.; Liu, X.; Wang, Y.; Liao, T.; et al. Water vapor variation and the effect of aerosols in China. Atmos. Environ. 2017, 165, 322-335. [CrossRef]

6. Chen, S.; Huang, J.; Kang, L.; Wang, H.; Ma, X.; He, Y.; Yuan, T.; Yang, B.; Huang, Z.; Zhang, G. Emission, transport, and radiative effects of mineral dust from the Taklimakan and Gobi deserts: Comparison of measurements and model results. Atmos. Chem. Phys. 2017, 17, 2401-2421. [CrossRef]

7. Rodríguez, S.; Alastuey, A.; Querol, X. A review of methods for long term in situ characterization of aerosol dust. Aeolian Res. 2012, 6, 55-74. [CrossRef]

8. Rosenfeld, D.; Rudich, Y.; Lahav, R. Desert dust suppressing precipitation: A possible desertification feedback loop. Proc. Natl. Acad. Sci. USA 2001, 98, 5975-5980. [CrossRef]

9. Tan, S.C.; Shi, G.Y.; Wang, H. Long-range transport of spring dust storms in Inner Mongolia and impact on the China seas. Atmos. Environ. 2012, 46, 299-308. [CrossRef]

10. Sun, J.; Zhang, M.; Liu, T. Spatial and temporal characteristics of dust storms in China and its surrounding regions, 1960-1999: Relations to source area and climate. J. Geophys. Res. Atmos. 2001, 106, 10325-10333. [CrossRef]

11. Zou, X.K.; Zhai, P.M. Relationship between vegetation coverage and spring dust storms over northern China. J. Geophys. Res. Atmos. 2004, 109, 1-9. [CrossRef]

12. Wu, J.; Kurosaki, Y.; Shinoda, M.; Kai, K. Regional characteristics of recent dust occurrence and its controlling factors in East Asia. Sci. Online Lett. Atmos. 2016, 12, 187-191. [CrossRef]

13. Zhang, Y.; Takahashi, M.; Guo, L. Analysis of the East Asian subtropical westerly jet simulated by CCSR/NIES/FRCGC coupled climate system model. J. Meteorol. Soc. Jpn. 2008, 86, 257-278. [CrossRef]

14. Goudie, A.S. Dust storms: Recent developments. J. Environ. Manag. 2009, 90, 89-94. [CrossRef]

15. Gui, K.; Che, H.; Wang, Y.; Wang, H.; Zhang, L.; Zhao, H.; Zheng, Y.; Sun, T.; Zhang, X. Satellite-derived PM2.5 concentration trends over Eastern China from 1998 to 2016: Relationships to emissions and meteorological parameters. Environ. Pollut. 2019, 247, 1125-1133. [CrossRef]

16. Che, H.; Gui, K.; Xia, X.; Wang, Y.; Holben, B.N.; Goloub, P.; Cuevas-Agulló, E.; Wang, H.; Zheng, Y.; Zhao, H.; et al. Large contribution of meteorological factors to inter-decadal changes in regional aerosol optical depth. Atmos. Chem. Phys. 2019, 19, 10497-10523. [CrossRef]

17. Wang, H.; Zhang, L.; Cao, X.; Zhang, Z.; Liang, J. A-Train satellite measurements of dust aerosol distributions over northern China. J. Quant. Spectrosc. Radiat. Transf. 2013, 122, 170-179. [CrossRef]

18. Lee, Y.C.; Yang, X.; Wenig, M. Transport of dusts from East Asian and non-East Asian sources to Hong Kong during dust storm related events 1996-2007. Atmos. Environ. 2010, 44, 3728-3738. [CrossRef]

19. Chen, Y.; Luo, B.; Xie, S.D. Characteristics of the long-range transport dust events in Chengdu, Southwest China. Atmos. Environ. 2015, 122, 713-722. [CrossRef]

20. Mikami, M.; Shi, G.Y.; Uno, I.; Yabuki, S.; Iwasaka, Y.; Yasui, M.; Aoki, T.; Tanaka, T.Y.; Kurosaki, Y.; Masuda, K.; et al. Aeolian dust experiment on climate impact: An overview of Japan-China joint project ADEC. Glob. Planet. Chang. 2006, 52, 142-172. [CrossRef] 
21. Duncan Fairlie, T.; Jacob, D.J.; Park, R.J. The impact of transpacific transport of mineral dust in the United States. Atmos. Environ. 2007, 41, 1251-1266. [CrossRef]

22. Creamean, J.M.; Suski, K.J.; Rosenfeld, D.; Cazorla, A.; Demott, P.J.; Sullivan, R.C.; White, A.B.; Ralph, F.; Minnis, P.; Comstock, J.M.; et al. Dust and biological aerosols. Science 2013, 339, 1572-1578. [CrossRef] [PubMed]

23. Wu, J.; Kai, K. Characteristics of outbreaks and their relation to strong wind and land surface conditions in the Gobi Desert and northern China, 1999-2013. Arid Land Stud. 2016, 26, 51-57.

24. Kai, K.; Minamoto, Y.; Nakamura, K.; Wang, M.; Kawai, K.; Ohara, K.; Noda, J.; Maki, T.; Davaanyam, E.; Sugimoto, N. Large-scale dust event in East Asia, as revealed by the Himawari-8 DUST RGB, lidar network observations, and field survey. E3S Web Conf. 2019, 99, 8-11. [CrossRef]

25. Gelaro, R.; McCarty, W.; Suárez, M.J.; Todling, R.; Molod, A.; Takacs, L.; Randles, C.A.; Darmenov, A.; Bosilovich, M.G.; Reichle, R.; et al. The modern-era retrospective analysis for research and applications, version 2(MERRA-2). J. Clim. 2017, 30, 5419-5454. [CrossRef] [PubMed]

26. Molod, A.; Takacs, L.; Suarez, M.; Bacmeister, J.; Song, I.-S.; Eichmann, A. The GEOS-5 Atmospheric General Circulation Model: Mean Climate and Development from MERRA to Fortuna; NASA: Washington, DC, USA, 2012.

27. Molod, A.; Takacs, L.; Suarez, M.; Bacmeister, J. Development of the GEOS-5 atmospheric general circulation model: Evolution from MERRA to MERRA2. Geosci. Model Dev. 2015, 8, 1339-1356. [CrossRef]

28. Levy, R.C.; Remer, L.A.; Kleidman, R.G.; Mattoo, S.; Ichoku, C.; Kahn, R.; Eck, T.F. Global evaluation of the Collection 5 MODIS dark-target aerosol products over land. Atmos. Chem. Phys. 2010, 10, 10399-10420. [CrossRef]

29. Remer, L.A.; Kaufman, Y.J.; Tanré, D.; Mattoo, S.; Chu, D.A.; Martins, J.V.; Li, R.-R.; Ichoku, C.; Levy, R.C.; Kleidman, R.G.; et al. The MODIS aerosol algorithm, products, and validation. J. Atmos.Sci. 2005, 62, 947-973. [CrossRef]

30. Kahn, R.A.; Gaitley, B.J.; Martonchik, J.V.; Diner, D.J.; Crean, K.A.; Holben, B. Multiangle Imaging Spectroradiometer (MISR) global aerosol optical depth validation based on 2 years of coincident Aerosol Robotic Network (AERONET) observations. J. Geophys. Res. Atmos. 2005, 110, 1-16. [CrossRef]

31. Holben, B.N.; Eck, T.F.; Slutsker, I.; Tanré, D.; Buis, J.P.; Setzer, A.; Vermote, E.; Reagan, J.A.; Kaufman, Y.J.; Nakajima, T; et al. AERONET_A federated instrument network and data archive for aerosol characterization. Remote Sens. Environ. 1998, 66, 1-16. [CrossRef]

32. Buchard, V.; Randles, C.A.; da Silva, A.M.; Darmenov, A.; Colarco, P.R.; Govindaraju, R.; Ferrare, R.; Hair, J.; Beyersdorf, A.J.; Ziemba, L.D.; et al. The MERRA-2 aerosol reanalysis, 1980 onward. Part II: Evaluation and case studies. J. Clim. 2017, 30, 6851-6872. [CrossRef]

33. Bessho, K.; Date, K.; Masahiro, H.; Ikeda, A.; Imai, T.; Inoue, H.; Kumagai, Y.; Miyakawa, T.; Murata, H.; Ohno, T.; et al. An introduction to Himawari-8/9-Japan's new-generation geostationary meteorological satellites. J. Meteorol. Soc. Jpn. 2016, 94, 151-183. [CrossRef]

34. Ackerman, S.; Platnick, S.; Bhartia, P.; Duncan, B.; L'Ecuyer, T.; Heidinger, A.; Skofronick-Jackson, G.; Loeb, N.; Schmit, T.; Smith, N. Satellites see the world's atmosphere. Am. Meteorol. Soc. 2019, 59, 1-53. [CrossRef]

35. Eck, T.F.; Holben, B.N.; Reid, J.S.; Dubovik, O.; Smirnov, A.; O’Neill, N.T.; Slutsker, I.; Kinne, S. Wavelength dependence of the optical depth of biomass burning, urban, and desert dust aerosols. J. Geophys. Res. 1999. [CrossRef]

36. Nobuo, S.; Tomoaki, N.; Atsushi, S.; Ichiro, M.; Yoshitaka, J.; Akiko, H.; Itsushi, U.; Yukari, H.; Keiya, Y.; Rei, K. Continuous Observations of Atmospheric Aerosols across East Asia; SPIE: Bellingham, WA, USA, 2015.

37. Allen, C.J.T.; Washington, R.; Engelstaedter, S. Dust emission and transport mechanisms in the central Sahara: Fennec ground-based observations from Bordj Badji Mokhtar, June 2011. J. Geophys. Res. Atmos. 2013, 118, 6212-6232. [CrossRef]

38. Cheng, T.; Peng, Y.; Feichter, J.; Tegen, I. An improvement on the dust emission scheme in the global aerosol-climate model ECHAM5-HAM. Atmos. Chem. Phys. 2008, 8, 1105-1117. [CrossRef]

39. Buchard, V.; da Silva, A.M.; Randles, C.A.; Colarco, P.; Ferrare, R.; Hair, J.; Hostetler, C.; Tackett, J.; Winker, D. Evaluation of the surface PM 2.5 in Version 1 of the NASA MERRA Aerosol Reanalysis over the United States. Atmos. Environ. 2016, 125, 100-111. [CrossRef]

40. Randles, C.A.; da Silva, A.M.; Buchard, V.; Darmenov, A.; Colarco, P.R.; Aquila, V.; Bian, H.; Nowottnick, E.P.; Pan, X.; Smirnov, A.; et al. The MERRA-2 Aerosol Assimilation; NASA Technical Report Series on Global Modeling and Data Assimilation; NASA: Washington, DC, USA, 2016; Volume 45, p. 143. 
41. Jing, Y.; Zhang, P.; Chen, L.; Xu, N. Integrated analysis of dust transport and budget in a severe asian dust event. Aerosol Air Qual. Res. 2017, 17, 2390-2400. [CrossRef]

42. Liu, L.; Guo, J.; Gong, H.; Li, Z.; Chen, W.; Wu, R.; Wang, L.; Xu, H.; Li, J.; Chen, D.; et al. Contrasting influence of Gobi and Taklimakan Deserts on the Dust Aerosols in Western North America. Geophys. Res. Lett. 2019, 46, 9064-9071. [CrossRef]

(C) 2020 by the authors. Licensee MDPI, Basel, Switzerland. This article is an open access article distributed under the terms and conditions of the Creative Commons Attribution (CC BY) license (http://creativecommons.org/licenses/by/4.0/). 